\title{
COGNITIVE PROFILE OF PATIENTS WITH RELAPSING REMITTING MULTIPLE SCLEROSIS
}

\author{
VIVIAN M. ANDRADE*, ORLANDO F.A. BUENO*, MARIA GABRIELA M. OLIVEIRA*, \\ ACARY S.B. OLIVEIRA** ENEDINA M.L. OLIVEIRA** MÔNICA C. MIRANDA**
}

\begin{abstract}
Multiple sclerosis (MS) is a common disease in Western countries of temperate/cold climate, but in tropical countries an increasing number of cases have been diagnosticated. Moved by the lack of information about cognitive dysfunction of Brazilian MS patients, the present study attempted to describe features of neuropsychological alterations in patients with relapsing remitting MS living in the city of São Paulo. They were compared to healthy volunteers, matched for age and education. In the absence of global intellectual deterioration, the patients had a deficit: a) in learning and verbal long-term memory tasks and in visual long-term memory of complex figure; b) in timed tasks, accounted for by a slowness of mental processes; c) in tasks with a motor component. Tendency to depression was observed; anxiety levels were normal.
\end{abstract}

KEY WORDS: multiple sclerosis, relapsing remitting, neuropsychological evaluation, memory, cognition.

\section{Perfil cognitivo de pacientes com esclerose múltipla do tipo surto-remissão}

RESUMO - A esclerose múltipla (EM) é doença comum em países de clima temperado/frio, mas também em países tropicais um crescente número de casos tem sido diagnosticado. Motivado pela escassez de informações acerca da cognição dos portadores de EM em nosso país, o presente estudo procurou traçar o perfil neuropsicológico de pacientes com EM da forma surto-remissão, residentes no município de São Paulo, os quais foram comparados a pessoas sadias, com idade e escolaridade semelhantes. A inteligência geral dos pacientes estava preservada mas foram detectados déficits: a) em tarefas de aprendizagem e de memória verbal e visual de figura complexa, ambas de longo prazo; b) em tarefas cronometradas, explicados por lentificação do processamento mental; c) em tarefas com componente motor. Tendência a depressão foi observada; os níveis de ansiedade encontravam-se normais.

PALAVRAS-CHAVE: esclerose múltipla, surto-remissão, avaliação neuropsicológica, memória, cognição.

Multiple sclerosis (MS), also referred to in the British Commonwealth as disseminated sclerosis and among French-speaking physicians as sclérose en plaques, is one of the most chronic neurologic diseases ${ }^{1}$. Diagnosis may be uncertain in the early stages of the disease, although the combination of (1) symptoms referable to white matter fiber tracts in optic nerves, brainstem and spinal cord, (2) a multiplicity of lesions, and (3) temporal dispersion of attacks eventually makes the diagnosis certain. According to clinical course, relapsing remitting (patients have a series of exacerbations of the disease with complete or partial remission) and steadily progressive (patients have progressive downhill course) are the two more frequent forms of presentation.

Universidade Federal de São Paulo (UNIFESP): *Departamento de Psicobiologia; **Departamento de Neurologia. Financial support: AFIP, CNPq. Aceite: 5-junho-1999.

Dr. Orlando F.A. Bueno - Departamento de Psicobiologia UNIFESP - Rua Botucatu 862, $1^{\circ}$ andar - 04023-062 São Paulo SP - Brasil. E-mail: mgabi@psicobio.epm.br 
The etiology of MS remains unknown, no cure is presently at hand and the prevalence is high. In many regions of several countries of Europe and North America the distribution of MS is high (prevalence of 30 or more per 100,000 population), with the prevalence increasing with increasing latitude ${ }^{2}$. In tropical countries as Brazil, recent studies have estimated a prevalence of 4.27 cases per 100,000 population in the City of São Paulo ${ }^{3}$, meaning that we are in a low frequency zone (less than 5 per 100,000), although this figure can change with new surveys. The standardization of diagnostic criteria carried out by Poser and collaborators ${ }^{4}$ and the general acceptance of the disability scale proposed by Kurtzke ${ }^{5}$ have constituted fundamental steps to promote the advancement of research in this area. Comparative studies using these international standards and aimed at elucidating the clinical profile and the evolutive course of the disease in countries of the southern hemisphere are being carried out. One interesting question have to do with possible differences or the lack of them in the manifestations of MS in tropical climate regions as compared to temperate and cold regions ${ }^{6,7}$.

It has often been pointed out that patients with MS, mainly in late stages, have decreased cognitive capacities, related to size and site of the plaques. These cognitive alterations, however, may appear also in mild stages ${ }^{8,9}$. This cognitive impoverishment was already registered by Charcot in the $19^{\text {th }}$ century ${ }^{9}$, but systematic cognitive studies have begun only recently. Memory and learning impairments are being repeatedly demonstrated since the late 60 s (e.g. $\left.{ }^{9-14}\right)$, while general intelligence and language seem to be less affected.

While a wealth of data concerning a variety of neuropsychological aspects of MS patients is continuously being gathered in northern countries (for reviews: ${ }^{9,15,16}$ ), in South American countries neuropsychological data are very scarce. Aiming to contribute to the partial filling of this gap, the present study attempted to describe a cognitive profile of relapsing remitting MS patients living in the City of São Paulo, SP and under treatment in a public hospital of this city.

\section{METHOD}

\section{Participants}

The participants were 25 patients with clinically definite MS, as diagnosed by the criteria of Poser et al. ${ }^{4}$ and classified as having the relapsing remitting course of the disease. Further criteria of inclusion were: at least 4 years of formal education, 18-60 years of age, no history of other psychiatric or neurologic disease, no history of alcohol or drug abuse, no other complicating medical condition. All the patients were physically independent, with scores between 0-6 in the Expanded Disability Status Scale (EDSS) ${ }^{5}$. No patient with lesions limited only to spinal cord was included. At the time of evaluation the disease was in a clinically inactive state. The first relapse of most patients occurred in the second or third decade of life; only one patient had the first relapse after 50 years of age. The average number of relapses was 3 in 8 years of disease. The patients ( $76 \%$ females) were volunteers recruited among patients under treatment in the Department of Neurology of UNIFESP/Hospital São Paulo or from the Associação Brasileira de Esclerose Múltipla (ABEM). All the patients were receiving symptomatic medication, either interferon-beta $1 \mathrm{~b}$ (on alternate days), azathioprine or methotrexate. Steroids were only prescribed to treat acute relapses of the disease.

The control group consisted of 24 volunteers (75\% females) who fulfilled the same basic criteria for inclusion except the disease. Table 1 presents the distribution of age and education of both groups and also shows the occupational status of the participants. As the disease progressed, the occupational status of many patients changed, as they became unemployed, retired or stopped studying.

\section{Neuropsychological evaluation}

The procedures and consent form used in this study were approved by the Medical Ethics Committee of the Universidade Federal de São Paulo.

The neuropsicological battery employed aimed to briefly investigate the main cognitive functions using tests already reported in the literature ${ }^{8,9}$ to make possible a comparison with international data. The choice of the tests was done in order to compare performance of patients with control subjects in several cognitive domains: general intelligence, memory (immediate and recent, verbal and non-verbal), perceptual and motor capacities, some aspects of language, and mood. The tests were administered by two trained psychologists. The order of 
Table 1. Demographic variables.

\begin{tabular}{|c|c|c|c|c|}
\hline & MS Patients $(n=25)$ & Control Subjects $(n=24)$ & $\mathrm{t}$ values & $\mathrm{p}$ \\
\hline Age in years mean (range) & $38.5(18-56)$ & $35.3(20-54)$ & 1.093 & 0.28 \\
\hline Education in years mean (range) & $12.4(6-20)$ & $13.9(4-20)$ & 1.216 & 0.23 \\
\hline Sex (males/females) & $6 / 19$ & $6 / 18$ & & \\
\hline Duration of disease in years mean (range) & $8.7(1-20)$ & - & & \\
\hline Number of relapses & 3.4 & - & & \\
\hline \multicolumn{5}{|l|}{ Marital status } \\
\hline Married & $13(52 \%)$ & $10(42 \%)$ & & \\
\hline Single & $9(36 \%)$ & $13(54 \%)$ & & \\
\hline Divorced/separated & $3(12 \%)$ & - & & \\
\hline Divorced/ remarried & - & $1(4 \%)$ & & \\
\hline \multicolumn{5}{|l|}{ Occupational status (before MS) } \\
\hline Managerial & $9(36 \%)$ & - & & \\
\hline Commercial & $5(20 \%)$ & - & & \\
\hline Technical & $5(20 \%)$ & - & & \\
\hline Housewife & $5(20 \%)$ & - & & \\
\hline Student & $1(4 \%)$ & - & & \\
\hline \multicolumn{5}{|l|}{ Occupational status (present) } \\
\hline Managerial & $2(8 \%)$ & $6(25 \%)$ & & \\
\hline Commercial & $3(12 \%)$ & $9(37.5 \%)$ & & \\
\hline Technical & $3(12 \%)$ & $2(8 \%)$ & & \\
\hline Housewife & $8(32 \%)$ & $3(12.5 \%)$ & & \\
\hline Student & $1(4 \%)$ & $4(17 \%)$ & & \\
\hline Unemployed & $3(12 \%)$ & & & \\
\hline Retired & $1(4 \%)$ & & & \\
\hline Retired by illness & $4(16 \%)$ & - & & \\
\hline \multicolumn{5}{|l|}{ School } \\
\hline Attending at present & $5(20 \%)$ & $11(46 \%)$ & & \\
\hline Stopped attending & $20(80 \%)$ & $13(54 \%)$ & & \\
\hline
\end{tabular}

MS, multiple sclerosis.

presentation of the tests was pseudo-ramdomized in order to prevent any distortion that might be caused by fatigue; rest periods during the application sessions were allowed depending on the physical and emotional states of the subjects. All of them appeared to be motivated to perform the cognitive tasks. The battery was applied in three sessions of 2 hours each, and consisted of the following tests:

a) a shortened version of the Wechsler Adult Intelligence Scale-Revised (WAIS-R), which included 5 verbal and 4 non-verbal subtests: Comprehension, Arithmetic, Similarities, Vocabulary, Digit Span, Digit Symbol, Picture Completion, Block Design, Picture Arrangement ${ }^{17}$.

b) three subtests of the Wechsler Memory Scale (WMS): Logical Memory, Visual Reproduction and Associate Learning ${ }^{17}$. 
c) Stroop Color Test. It is a measure of cognitive flexibility and focused attention. The Victoria version was used ${ }^{18}$.

d) Rey-Osterrieth Complex Figure. It evaluates the perceptual and motor capacities required to copy a complex figure, and assess delayed visual memory through a recovery test 30 minutes later ${ }^{18}$.

e) Corsi Block-tapping Test. It evaluates the immediate memory span for visuospatial material ${ }^{17}$.

f) Word Fluency Test (FAS). It evaluates verbal fluency and access to lexicon ${ }^{18}$.

g) Naming and Memory for Objects. Procedure I - Incidental memory: the subject is asked to name 15 small objects of everyday use, presented one at a time. Immediately after he/she is asked to remember which objects he /she has seen with no previous knowledge of the memory requirement. Procedure II - Intentional memory: the same task using 15 different objects, except that the subject knows in advance that a retention test will be done. Procedure III - Recognition test, 30 minutes later, of all objects presented among others not shown before.

h) Beck Depression Inventory ${ }^{19}$.

i) State-Trait Anxiety Inventory (STAI) ${ }^{19,20}$.

The subjects of the present study had also participated in a related study to be reported separatedly in which word free recall tests were administered, intermingled with the battery listed above.

The Student t test was used to analyse statistically the results. For differences considered to be statistically significant $(\mathrm{p}<0.05)$, we also calculated the effect size, that expresses the degree to which two sample means differ in terms of pooled standard deviations ${ }^{21}$. Conventionally, a medium effect size is about $50-79 \%$ of the group standard deviation and a large effect size is $80 \%$ or more of the standard deviation. When appropriate, some results were analysed by a 2-way ANOVA followed by the Tukey a posteriori test.

\section{RESULTS}

Table 2 shows cognitive test scores means, standard deviations, $t$ values and probability values derived from Student test comparisons. Effect size values of significant differences are also indicated. These ranged from 0.68-0.76 (medium degree of separation between means) to 0.81-1.12 (large degree of separation).

There were no significant differences between the MS patients and their controls regarding Full scale IQ and Verbal IQ of the WAIS-R.

The MS patients showed normal performance in the span measures, in both digit span and visuospatial span (Corsi block-tapping test). The backward digit span as well as the backward visuospatial span also were not different from controls.

Significant differences were found in tests that involved a motor component, such as the Performance IQ that encompasses the Picture Completion, the Picture Arrangement and the Digit Symbol tests. In the delayed test of the Rey-Osterrieth Figure the patients' performance was also lower than that of the controls (the effect size indicated a medium degree of separation between the means of both groups), but the copy of this figure was within the normal range.

Immediate and delayed visual reproduction is a visual drawing memory test in which no differences were apparent between patients and their controls, nor there was any interaction group $\mathrm{x}$ trial $[\mathrm{F}(1,45)=0.914 ; \mathrm{p}=0.34]$, as revealed by a 2 -way ANOVA $[\mathrm{F}(1,45)=2.68 ; \mathrm{p}=0.1]$. The trial effect was significant $[\mathrm{F}(1,45)=40.96 ; \mathrm{p}<0.001]$, reflecting the decay of performance in the delayed test in both groups (Fig 1C).

Significant differences in tests that evaluate cognitive functions relatively uncontaminated with a motor component were also found: FAS (medium degree of separation between means, according to the effect size value), Stroop Color, Associate Learning (immediate and delayed), Logical Memory (immediate and delayed; medium degree of separation of means). Incidental and intentional memory as well as delayed recognition of concrete material (objects from daily usage) were normal.

A 2-way ANOVA was performed to verify if Associate Learning had occurred. It showed an increasing learning curve for both groups $[\mathrm{F}(3,141)=230.67 ; \mathrm{p}<0.0001]$, and no interaction between 
Table 2. Neuropsychological evaluation.

\begin{tabular}{|c|c|c|c|c|}
\hline MS I & Patients (mean \pm sd) & Control Subjects (mean \pm sd) & $\mathrm{t}$ values & $\mathrm{p}$ \\
\hline \multicolumn{5}{|l|}{ WAIS-R } \\
\hline Full Scale IQ & $104.8 \pm 17.0$ & $111.1 \pm 14.6$ & 1.364 & 0.17 \\
\hline Verbal IQ & $109.8 \pm 17.0$ & $110.8 \pm 14.3$ & 0.21 & 0.82 \\
\hline Vocabulary & $9.2 \pm 2.3$ & $9.3 \pm 2.2$ & 0.155 & 0.90 \\
\hline Arithmetic & $8.2 \pm 3.3$ & $8.9 \pm 2.8$ & 0.825 & 0.41 \\
\hline Similarities & $10.2 \pm 2.7$ & $10.0 \pm 2.5$ & 0.319 & 0.75 \\
\hline Digit Span Forward & $5.9 \pm 1.4$ & $6.5 \pm 1.9$ & 1.193 & 0.23 \\
\hline Digit Span Backward & $4.0 \pm 1.3$ & $4.4 \pm 1.5$ & 1.267 & 0.30 \\
\hline Comprehension & $11.3 \pm 3.0$ & $10.9 \pm 2.2$ & 0.55 & 0.58 \\
\hline Performance IQ & $96.4 \pm 14.9$ & $108.1 \pm 15.9$ & 2.596 & $0.01^{\mathrm{d}}$ \\
\hline Picture Completion & $8.2 \pm 2.4$ & $9.5 \pm 2.5$ & 1.789 & 0.08 \\
\hline Picture Arrangement & $7.5 \pm 2.5$ & $9.6 \pm 2.6$ & 2.812 & $0.007^{\mathrm{f}}$ \\
\hline Block Design & $8.2 \pm 2.0$ & $8.6 \pm 1.5$ & 0.770 & 0.44 \\
\hline Digit Symbol & $6.6 \pm 2.5$ & $9.3 \pm 2.5$ & 3.802 & $0.0004^{\mathrm{i}}$ \\
\hline \multicolumn{5}{|l|}{ CORSI BLOCK-TAPPING } \\
\hline Forward & $5.0 \pm 1.1$ & $5.5 \pm 1.0$ & 1.713 & 0.09 \\
\hline Backward & $4.4 \pm 0.8$ & $4.8 \pm 0.8$ & 1.367 & 0.17 \\
\hline FAS & $32.2 \pm 9.9$ & $39.3 \pm 9.3$ & 2.6 & $0.01^{\mathrm{c}}$ \\
\hline \multicolumn{5}{|l|}{ Rey-Osterrieth } \\
\hline Copy & $33.5 \pm 4.5$ & $35.6 \pm 5.5$ & 1.460 & 0.15 \\
\hline Delayed & $15.5 \pm 8.4$ & $20.8 \pm 6.9$ & 2.395 & $0.02^{b}$ \\
\hline \multicolumn{5}{|l|}{ WMS } \\
\hline Logical Memory Immediate & $21.2 \pm 6.8$ & $26.3 \pm 6.9$ & 2.590 & $0.01^{\mathrm{c}}$ \\
\hline Logical Memory delayed & $17.7 \pm 8.3$ & $22.8 \pm 6.7$ & 2.339 & $0.02^{\mathrm{a}}$ \\
\hline Visual Reproducion Immediate & $30.6 \pm 6.7$ & $33.3 \pm 6.3$ & 1.438 & 0.15 \\
\hline Visual Reproducion delayed & $22.8 \pm 10.6$ & $27.3 \pm 8.5$ & 1.615 & 0.11 \\
\hline \multicolumn{5}{|l|}{ Associate Learning } \\
\hline Trial I & $2.7 \pm 1.0$ & $4.1 \pm 1.5$ & 4.045 & $0.0001^{\mathrm{j}}$ \\
\hline Trial II & $4.2 \pm 1.2$ & $5.5 \pm 1.4$ & 3.476 & $0.001^{\mathrm{h}}$ \\
\hline Trial III & $5.0 \pm 1.4$ & $6.1 \pm 1.3$ & 2.986 & $0.004^{\mathrm{e}}$ \\
\hline Trial IV & $7.2 \pm 1.8$ & $8.4 \pm 1.7$ & 2.433 & $0.01^{\mathrm{b}}$ \\
\hline \multicolumn{5}{|l|}{ Objects } \\
\hline Incidental & $9.6 \pm 2.3$ & $10.6 \pm 1.3$ & 1.810 & 0.07 \\
\hline Intentional & $8.9 \pm 2.2$ & $9.4 \pm 2.6$ & 1.658 & 0.10 \\
\hline Delayed Recognition & $9.6 \pm 1.0$ & $9.9 \pm 0.3$ & 1.358 & 0.18 \\
\hline \multicolumn{5}{|l|}{ Stroop color test } \\
\hline \multicolumn{5}{|l|}{ Card I } \\
\hline Reading time & $18.5 \pm 7.1$ & $13.8 \pm 4.5$ & 2.731 & $0.009^{e}$ \\
\hline Errors & $0.3 \pm 0.7$ & $0.1 \pm 0.4$ & 1.225 & 0.22 \\
\hline \multicolumn{5}{|l|}{ Card II } \\
\hline Reading time & $19.9 \pm 10.0$ & $16.6 \pm 3.8$ & 2.017 & 0.50 \\
\hline Errors & $0.2 \pm 0.8$ & $0.4 \pm 0.2$ & 1.171 & 0.24 \\
\hline \multicolumn{5}{|l|}{ Card III } \\
\hline Reading time & $35.8 \pm 14.2$ & $26.7 \pm 7.2$ & 2.793 & $0.007^{\mathrm{e}}$ \\
\hline Errors & $1.2 \pm 1.6$ & $0.5 \pm 1.5$ & 1.431 & 0.15 \\
\hline
\end{tabular}

MS, multiple sclerosis; WAIS-R, Wechsler Adult Inteligence Scale-Revised; IQ, Intelligence Quotient; WMS, Wechsler Memory Scale. Effect size values: ${ }^{\mathrm{a}}=0.68 ;{ }^{\mathrm{b}}=0.69 ;{ }^{\mathrm{c}}=0.74 ;{ }^{\mathrm{d}}=0.76 ;{ }^{\mathrm{e}}=0.81 ;{ }^{\mathrm{f}}=0.82 ;{ }^{\mathrm{g}}=0.85 ;{ }^{\mathrm{h}}=1.0 ;{ }^{\mathrm{i}}=1.08 ;{ }^{\mathrm{j}}=1.12$. 

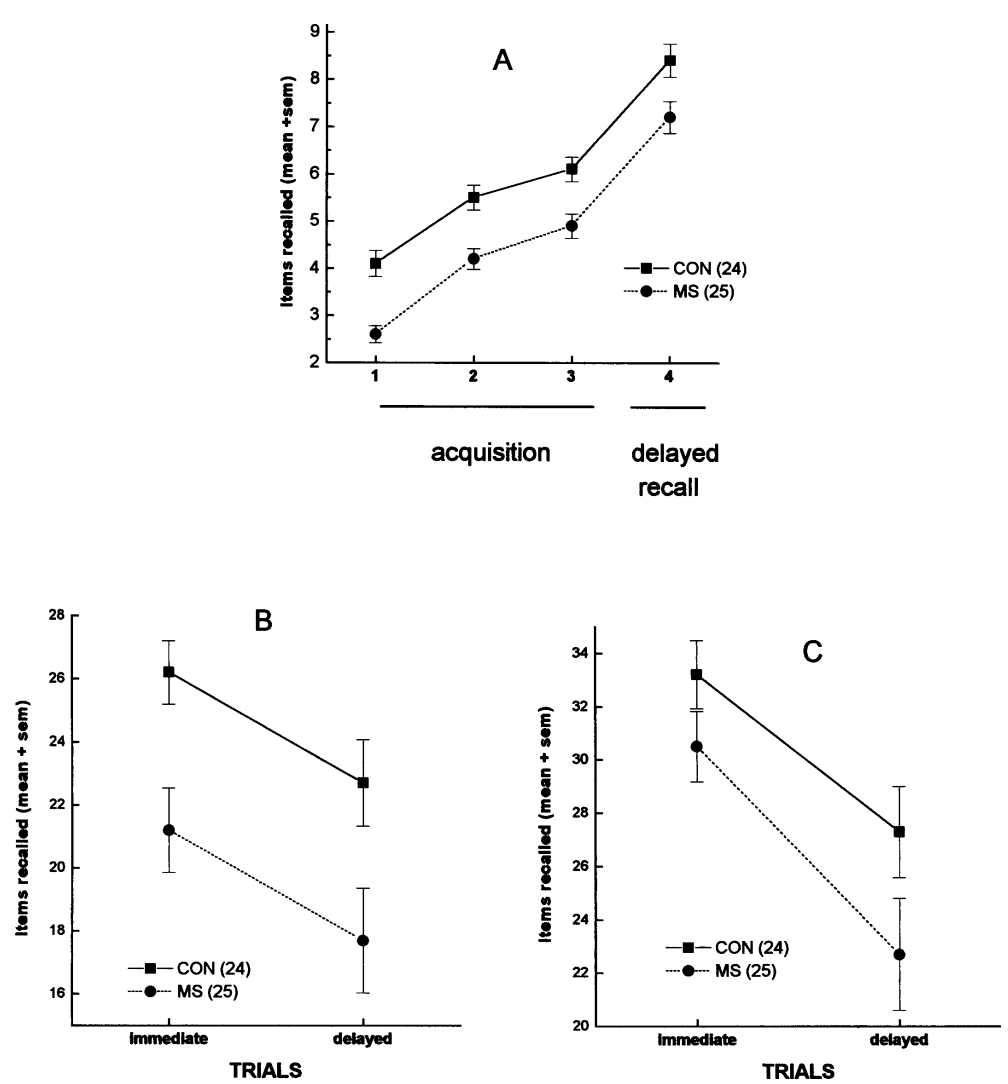

Fig 1. Number of items recalled in three subtests of the WMS: (A) acquisition trials and delayed recall of the Associate Learning subtest; (B) immediate and delayed recall of the Logical Memory subtest; $(C)$ immediate and delayed reproduction of the Visual Reproduction subtest.

groups and trials $[\mathrm{F}(1,141)=0.2499 ; \mathrm{p}=0.86]$, indicating that the rate of learning was similar in both groups, although the amount of learning of the controls was higher than that of the patients [F(1,47)=13.34; $\mathrm{p}=0.0007]$ (Fig 1A).

Regarding the Logical Memory Test (Fig 1B), a 2-way ANOVA showed that in the second trial the subjects remembered less words than in the first trial $[\mathrm{F}(1,47)=6.308 ; \mathrm{p}=0.01]$. There was no group $\mathrm{x}$ trial interaction $[\mathrm{F}(1,47)=0.0006 ; \mathrm{p}=0.98]$, indicating that the rate of forgetting was similar in both groups, in spite of the fact that the patients remembered less fragments of the story $[F(1,47)=63.515 ; \mathrm{p}<0.0001)$.

The number of errors in the Stroop Color test was not greater in the patients group than in the controls group in none of the three cards that constitute the task, but the patients were significantly slower in reading the words of Cards I and III.

As shown in Table 3, the patients showed a higher score on the Beck Scale than the controls. The anxiety inventory did not reveal differences between the groups. 
Table 3.- Mood evaluation.

\begin{tabular}{lcccc}
\hline & $\begin{array}{c}\text { MS Patients } \\
(\text { mean } \pm \text { sd })\end{array}$ & $\begin{array}{c}\text { Control Subjects } \\
(\text { mean } \pm \text { sd })\end{array}$ & t values & p \\
\hline BECK & $15.5( \pm 11.3)$ & $7.0( \pm 6.1)$ & 3.122 & $0.003^{\mathrm{a}}$ \\
STAI & $44.6( \pm 3.5)$ & $43.8( \pm 4.9)$ & 0.539 & 0.5 \\
Trait & $46.5( \pm 4.2)$ & $45.9( \pm 4.9)$ & 0.343 & 0.7 \\
State & 4.5 & & \\
\hline
\end{tabular}

MS, multiple sclerosis; BECK, Beck Depression Inventory; STAI, State-Trait Anxiety Inventory. Effect size values: ${ }^{a}=0.98$.

\section{DISCUSSION}

The Digit Span test is widely used to measure verbal short-term memory and also evaluates auditory attention ${ }^{17}$, while the blocks of Corsi do the same thing with visuospatial material. The results

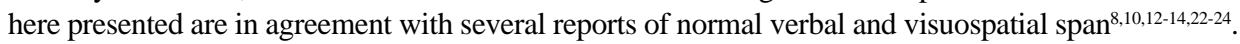

The known sensorimotor disturbances presented by MS patients may cause marked impairments on tasks that require motor responses ${ }^{11,14,25}$. Thus, disturbances in motor function could explain the poorer performance of our MS patients in some tasks contaminated with motor components, as the Digit Symbols and the Picture Arrangement tests. Impairment on these tests was reported previously ${ }^{8,26,27}$. Nonetheless, motor disturbances cannot account for deficits in many other tests. For instance, the score attained by our patients in the delayed Osterrieth-Rey Figure was low, but the copy was as good as the controls. Thus, it is necessary to invoke further impairment in other cognitive functions to explain the deficit in this delayed test.

The WAIS Similarities was found to be impaired by Klonoff et al. ${ }^{8}$ but not by others ${ }^{10,14}$. Deficits in the WAIS Block Design are not commonly reported. To our knowledge, in this latter test and in other tests of the WAIS battery, only Rao et al. ${ }^{28}$ have found significant differences in part of their sample of MS patients.

Deficits in planning and organizational skills are generally associated with disorders in the frontal systems. In our patients, the constructional ability, as evaluated by the copy of the ReyOsterrieth Figure was found to be within the normal limits; organizational, planning and copying abilities were not loosed, although slowness had been observed in some cases. Backward span requires additional mental processing and therefore can be considered a test of working memory, a function believed to be related to executive frontal systems ${ }^{29}$. Both verbal and visuospatial backward span were found to be normal. Thus, the executive frontal functions of our patients do not appear to be affected by the disease. Nonetheless, evidence for frontal dysfunction was reported by some authors based on the Wisconsin Card Sorting Test ${ }^{22,30}$, but Beatty and Monson ${ }^{31}$ interpreted the results usually obtained in MS as a deficit in concept formation.

The Stroop test revealed that the patients were slower than the control subjects in reading the words, a result that is in agreement with Jennekens-Schinkel et al. ${ }^{32}$ and van den Burg et al. ${ }^{34}$ who obtained a similar result. Information processing speed assessed by different techiques was reported by others to be lower as well in MS patients ${ }^{14,25,33}$.

Disorders in language functions were not detected by the Vocabulary subtest of the WAIS-R and by object naming. Naming was also found to be undisturbed in previous reports ${ }^{32.33}$. Word generation was unimpaired in one study ${ }^{32}$, but in the present study the patients produced a significantly smaller number of words in the FAS test, in agreement with most published results that show that 
impaired verbal fluency is a common finding in MS patients ${ }^{8,22,23,26,30}$. A deficit in word generation can be due to a slowing in mental processes, as the test requires the subject to produce as many words as possible within a fixed limit of time.

Immediate and delayed measures of Visual Reproduction were not significantly reduced in our patients. Memory for concrete objects was not impaired at all. In contrast, performance on tests that involve immediate and delayed verbal memory (Logical Memory and Paired Associate Learning) was impaired. This pattern of results suggests a deficit specific to verbal memory and verbal learning. Running counter to this hypothesis, the delayed recall of the Complex Figure of Rey-Osterrieth, a nonverbal memory test, was also poorer in our MS group. No explanation is available at the time for these discrepancies on memory measures, but one can speculate that the complexity of the task constitutes an important factor in determining memory impairments in these patients, as the tasks that were impaired, Logical Memory, Paired Associates and Rey-Osterrieth Figure seem to be the more complex tests, either in the number of items to be remembered or in the structure of the test.

How do our results in long-term memory tests compare to results in similar tasks reported in the international literature? The WMS Logical Memory and similar story recall tests are consistently found to be impaired in patiens with $\mathrm{MS}^{12,13,23,28}$, as well as the difficult pairs and the delayed testing of paired associates ${ }^{8,13,24,35}$. Visual reproduction was also found to be impaired by Rao et al. ${ }^{13}$ in chronic progressive patients.

Depression appears with a high rate of occurrence in patients with $\mathrm{MS}^{36}$. As cognitive impairment occurs in depressed patients, the cognitive impoverishment of patients with MS may be related to the their depressive state. In our sample, the patients attained higher scores on the Beck inventory than the controls, but their mean score of $15.5 \pm 11.3$ is not indicative of clinical depression ${ }^{19}$. A similar result in relapsing remitting patients was also found by others ${ }^{33,37}$, who considered that the depression found in their patients, although more pronounced than in normal people, cannot account for their cognitive deficits. It may be concluded, then, that the results of the group as a whole cannot be explained by depressive state, although it cannot be ruled out that depression had affected the individual results of some patients. Anxiety, on the contrary, remained in the same levels attained by the controls of our sample.

Changes in the professional life of the patients, reflecting probably in their financial status, had occurred as the demographic data suggest (Table 1). It is clear that the disease has an impact on the lives of the patients not restricted to their physical conditions, but also affecting their social functioning, family relationships, employment conditions, and their psychic and cognitive conditions ${ }^{38}$.

In the absence of global intellectual deterioration, the patients presented a deficit in performing several cognitive tests. The pattern of deficits seen in our MS relapsing remitting patients comprises: a) impairment in verbal and visual memory and learning tasks; b) impairment in timed tasks, accounted for by a slowness of mental processes; c) impairment in tasks with a motor component, explained, at least partially, by a difficulty in perform motor responses. Some of these tasks, however, are also timed (e.g. Digit Symbols), so the deficit may lie on the slowness of processing instead of on impairment of motor functioning.

These results are similar to those obtained in neuropsychological studies of European and North American countries. Although clearly impaired, the magnitude of the deficits can be classified as moderate. Some authors, indeed, have found less severe impairments on cognitive tests of relapsing remitting patients than in chronic progressive patients ${ }^{22,33}$, but the question whether the degree of cognitive impairment depends or not on the type of course of disease is still a matter for debate. The degree of cognitive impairment is variable but the incidence is high even in patients physically independent. According to Rao and his colleagues ${ }^{28}$, some degree of cognitive impairment affects about $54 \%$ to $65 \%$ of the patients. 


\section{REFERENCES}

1. McFarlin DE, McFarland HF. Multiple sclerosis (First of two parts). N Engl J Med 1982;307:1183-1188.

2. Kurtzke JF. Geographic distribution of multiple sclerosis: an update with special reference to Europe and the Mediterranean region. Acta Neurol Scand 1980;62:65-80.

3. Callegaro D, Delolio CA, Radvany J, Tilbery CP, Mendonça RA, Melo ACP. Prevalence of multiple sclerosis in the city of São-Paulo, Brazil, in 1990. Neuroepidemiology 1992;11:11-14.

4. Poser CM, Paty DW, Scheinberg L, et al. New diagnostic criteria for multiple sclerosis: guidelines for research protocols. Ann Neurol 1983;13:227-231.

5. Kurtzke JF. Rating neurological impairment in multiple sclerosis: an expanded disability status scale (EDSS). Neurology 1983;33:1444-1452.

6. Papais-Alvarenga RM, Santos CMM, Abreu JS et al. Esclerose múltipla (EM): perfil clínico e evolutivo no município do Rio de Janeiro. Rev Bras Neurol 1995;31:75-87.

7. Lana-Peixoto MA, Lana-Peixoto MIV. Is multiple sclerosis in Brazil and Asia alike? Arq Neuropsiquiatr 1992;50:419-425.

8. Klonoff H, Clark C, Oger J, Paty D, Li D. Neuropsychological performance in patients with mild multiple sclerosis. J Nerv Ment Dis 1991;179:127-131.

9. Rao SM. Neuropsychology of multiple sclerosis: a critical review. J Clin Exp Neuropsychol 1986;8:503-542.

10. Jambor KL. Cognitive functioning in multiple sclerosis. Br J Psychiatry 1969;115:765-775.

11. Beatty PA, Gange, JJ. Neuropsychological aspects of multiple sclerosis. J Nerv Ment Dis 1977;164: 42-50.

12. Grant I, McDonald WI, Trimble MR, Smith E, Reed R. Deficient learning and memory in early and middle phases of multiple sclerosis. J Neurol Neurosurg Psychiatry 1984;47:250-255.

13. Rao SM, Hammeke TA, McQuillen MP, Khatri BO, Lloyd MA. Memory disturbance in chronic progressive multiple sclerosis. Arch Neurol 1984;41:625-631.

14. Litvan I, Grafman J, Vendrell P, Martinez JM. Slowed information processing in multiple sclerosis. Arch Neurol 1988;45:281-285.

15. Fennell EB, Smith MC. Neuropsychological assessment. In Rao SM (ed.) Neurobehavioral aspects of multiple sclerosis. New York: Oxford Univ Press, 1990:63-81.

16. Grafman J, Rao SM, Litvan I. Disorders of memory. In Rao SM (ed) Neurobehavioral aspects of multiple sclerosis. New York: Oxford Univ Press, 1990:102-117.

17. Lezak MD. Neuropsychological assessment. 3.Ed. New York: Oxford Univ Press, 1995.

18. Spreen O, Strauss E. A compendium of neuropsychological tests: administration, norms, and commentary. New York: Oxford Univ Press, 1991.

19. Gorenstein C, Pompéia S, Andrade A. Scores of Brazilian university students on the Beck depression and the state-trait anxiety inventories. Psychol Rep 1995;77:635-641.

20. Biaggio AMB, Natalício L. Manual para o inventário de ansiedade traço-estado (IDATE). Rio de Janeiro: Centro Editor de Psicologia Aplicada-CEPA, 1979.

21. Portney LG, Watkins MP. Foundations of clinical research. Applications to practice. Norwalk, Connecticut: Appleton \& Lange, 1993.

22. Heaton RK, Nelson LM, Thompson DS, Burks JS, Franklin GM. Neuropsychological findings in relapsing-remitting and chronic-progressive multiple sclerosis. J Consult Clin Psychol 1985;58:103-110.

23. Rao SM, Leo GJ, St.Aubin-Faubert P. On the nature of memory disturbance in multiple sclerosis. J Clin Exp Neuropsychol 1989;11:699-712.

24. Jennekens-Schinkel A, van der Velde EA, Sanders EACM, Lanser JBK. Memory and learning in outpatients with quiescent multiple sclerosis. J Neurol Sci 1990;95:311-325.

25. Kujala P, Portin R, Revonsuo A, Ruutiainen J. Automatic and controlled information processing in multiple sclerosis. Brain 1994;117:1115-1126.

26. Beatty WW, Goodkin DE, Monson N, Beatty PA, Hertsgaard D. Anterograde and retrograde amnesia in patients with chronic progressive multiple sclerosis. Arch Neurol 1988;45:611-619.

27. Beatty WW, Monson N. Picture and motor sequencing in multiple sclerosis. J Clin Exp Neuropsychol 1994;16:165-172.

28. Rao SM, Leo GJ, Bernardin L, Unverzagt F. Cognitive dysfunction in multiple sclerosis: I. Frequency, patterns, and prediction. Neurology 1991;41:685-691.

29. Baddeley A. Recent developments in working memory. Curr Opin Neurobiol 1998;8:234-238

30. Beatty WW, Goodkin DE, Beatty PA, Monson N. Frontal lobe dysfunction and memory impairment in patients with chronic progressive multiple sclerosis. Brain Cog 1989;11:73-86.

31. Beatty WW, Monson N. Problem solving by patients with multiple sclerosis: comparison of performance on the Wisconsin and California Card Sorting Tests. J Int Neuropsychol Soc 1996;2:134-140.

32. Jennekens-Schinkel A, Lanser JBK, van der Velde EA, Sanders EACM. Performances of multiple sclerosis patients in tasks requiring language and visuoconstruction: assessment of patients in quiescent disease stages. J Neurol Sci 1990;95:89-103.

33. Beatty WW, Goodkin DE, Monson, N, Beatty PA. Cognitive disturbances in patients with relapsing remitting multiple sclerosis. Arch Neurol 1989;46:1113-1119.

34. van den Burg W, van Zomeren AH, Minderhoud JM. Cognitive impairment in patients with multiple sclerosis and mild physical disability. Arch Neurol 1987;44:494-501.

35. Grafman J, Rao S, Bernardin L, Leo GJ. Automatic memory processes in patients with multiple sclerosis. Arch Neurol 1991;48:1072-1075.

36. Sadovnick AD, Remick RA, Allen J et al. Depression and multiple sclerosis. Neurology 1996;46:628-632.

37. Good K, Clark CM, Oger J, Paty D, Klonoff H. Cognitive impairment and depression in mild multiple sclerosis. J Nerv Ment Dis 1992;180:730-732.

38. Sanvito WL, Tilbery CP. O impacto social e econômico da esclerose múltipla. Rev Bras Med 1996;53:757-760. 